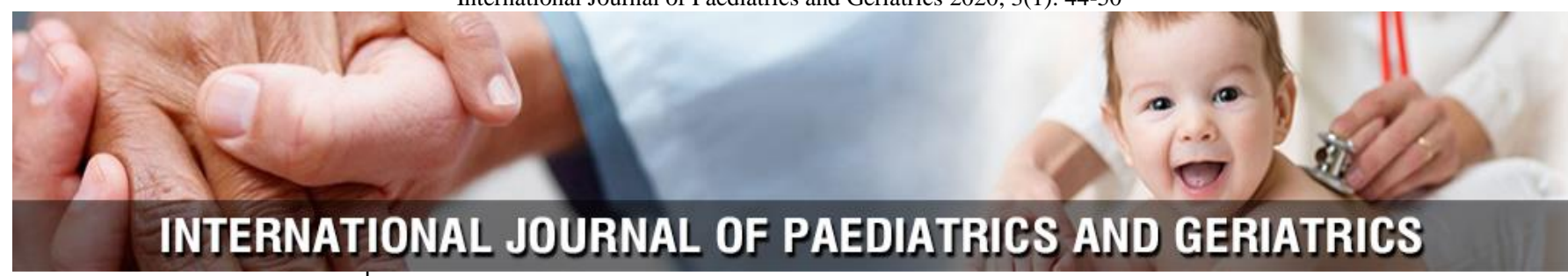

P-ISSN: 2664-3685

E-ISSN: 2664-3693

IJPG 2020; 3(1): 44-50

Received: 12-11-2019

Accepted: 20-12-2019

Dr. VS Anjankumar MD

Associate Professor of

Pediatrics, Sri Venkateswara

Medical College, Tirupati,

Andhra Pradesh, India

Dr. K Sivaramudu

Assistant Professor,

Department of Pediatrics, Sri

Venkateswara Medical College,

Tirupati, Andhra Pradesh,

India

Dr. I Bhaskar Naik

Assistent Professor,

Department of Pediatrics, Sri

Venkateswara Medical College,

Tirupati, Andhra Pradesh,

India

T Jayachandra Naidu MD Professor, Department of Pediatrics, Sri Venkateswara Medical College Tirupati, Andhra Pradesh, India

Dr. D Priyanka

Resident, Department of Pediatrics, Sri Venkateswara

Medical College Tirupati,

Andhra Pradesh, India

\section{S Suchitha}

Pharm. D Intern, Department of Pharmacy Practice, Sri

Padmavathi School of

Pharmacy, Tiruchanoor,

Tirupathi, Andhra Pradesh, India
Corresponding Author: Dr. VS Anjankumar MD Associate Professor of Pediatrics, Sri Venkateswara Medical College, Tirupati, Andhra Pradesh, India

\section{Efficacy of bubble continous positive airway pressure in newborns with respiratory distress and its outcome in tertiary care hospital, Tirupathi}

\author{
Dr. VS Anjankumar MD, Dr. K Sivaramudu, Dr. I Bhaskar Naik, T \\ Jayachandra Naidu MD, Dr. D Priyanka and S Suchitha
}

DOI: https://doi.org/10.33545/26643685.2020.v3.i1a.90

\begin{abstract}
Background: Respiratory distress is one of the commonest emergency occurring mostly within the first 48-72 hours of life. Bubble continuous positive airway pressure (bCPAP) is essential to manage acute respiratory distress in neonates.

Method: A Hospital based prospective observational study was done at SNCU at Department of Pediatrics, Sri Venkateswara Ramnarayan Ruia Government General Hospital, Tirupati from October 2017 to September 2018. Efficacy of bCPAP was judged based on Downe /SAS scoring.

Results: Out of 171 babies who were managed with bCPAP, it proved effective in 118 babies (69\%). The results analyzed based on gender and gestational age were found statistically significant difference $(p<0.05)$ and the results analyzed based on birth weight found no statistically significant difference in the outcome between the two groups ( $p>0.05$ ). The mean age for initiation of treatment is $9.39 \pm 15.022$ hours. Overall Mean duration on bCPAP was $24.24 \pm 18.22$. The success rate was more in babies with RDS $68.2 \%$. There was a significant improvement in Downe/SAS scores in babies with RDS, Pneumonia, MAS and TTNB. The complications were more in failure group. Study of mortality rate was more in the failure group $81 \%$ and the survival rate was more in success group $100 \%$.

Conclusion: CPAP appears to be the best option to manage infants with respiratory distress at SNCUs of peripheral levels.
\end{abstract}

Keywords: respiratory distress syndrome (RDS), bubble CPAP, Downe score/SAS score, meconium aspiration syndrome (MAS), transient tachypnea of new borns (TTNB)

\section{Introduction}

India constitutes one fifth of global live births and in neonatal deaths more than a quarter. In 2013,in India nearly 0.75 million neonates died, which was the highest in the world [1] Respiratory distress is one of the commonest emergency occurring mostly within the first 48 72 hours of life ${ }^{[2]}$. Respiratory distress in the neonate is diagnosed by tachypnoea or respiratory rate of more than 60/minute, chest indrawings or retractions, noisy respiration in the form of grunt, stridor or wheeze ${ }^{[3]}$. Respiratory distress severity is assessed by Silverman Anderson Score (SAS) ${ }^{[4]}$ in preterms and with Downe score ${ }^{[5]}$ in late pre terms \& term babies. Failure of early recognition and management of respiratory distress leads to short and long-term complications, including BPD, respiratory failure and even death ${ }^{[6]}$. Respiratory support to manage acute respiratory distress in neonates can be provided by continuous positive airway pressure (CPAP) or mechanical ventilation ${ }^{[7]}$. CPAP is a non-invasive form of respiratory support which does not require complex technical expertise. CPAP can be applied via a face mask, nasopharyngeal tube, or nasal prongs, using a conventional ventilator, bubble circuit or a CPAP driver. Bubble CPAP (bCPAP) is one of the low cost nasal CPAP delivering systems, with underwater seal. CPAP has been studied extensively in pre terms with respiratory distress syndrome (RDS) or hyaline membrane disease (HMD). But with the benefits of CPAP, a variety of neonatal respiratory conditions can be managed with it alone ${ }^{[8,9]}$

\section{Objectives}

To determine the efficacy of Bubble Continuous Positive Airway Pressure in newborns with respiratory distress in SNCU. 


\section{Method}

A Hospital based prospective observational study was done at SNCU at Department of Pediatrics, Sri Venkateswara Ramnarayan Ruia Government General Hospital, Tirupati from October 2017 to September 2018. All newborns with respiratory distress who were admitted at SNCU at Department of Pediatrics, Sri Venkateswara Ramnarayan Ruia Government General Hospital, Tirupati during the study period were included based on inclusion and exclusion criteria. Permission was obtained from institutional ethics committee, Sri Venkateswara Medical College, Tirupati before starting the study. Baby's mother or caretaker was explained about the condition and the study in their own language and consent was taken before the newborn was recruited into the study.

\subsection{Inclusion criteria}

1. In preterm babies with Silverman Anderson score 3-6.

2. In term babies with Downe Score $4-6$.

\subsection{Exclusion criteria}

1. Neonates with congenital anomalies.

2. Neonates with severe cardiovascular instability

3. Neonates requiring intubation at birth

4. Pneumothorax and other air leaks

5. Parents not willing to give consent

Details of birth history, risk factors in pregnancy, type of delivery, and need for resuscitation were recorded. Newborns were then connected to FISCHER \& PAYKEL bubbleCPAP device with HUDSON nasal prongs of appropriate size according to the birth weight.

All babies were nursed under radiant warmers on servocontrolled mode. Orogastric tubes were inserted and connected to open syringes (without piston) for venting. Strict asepsis was observed. Bubble CPAP was started with settings of CPAP - $5 \mathrm{cms}$ of $\mathrm{H} 2 \mathrm{O}$ and $\mathrm{FiO} 250 \%$ and flow rate 5 lit / min. These settings were adjusted accordingly to maintain pulse oximeter saturation between $88-94 \%$. Babies with a diagnosis of RDS were given surfactant if indicated and this was done by INSURE (Intubate, Surfactant Extubate) technique and babies were then put back on bCPAP. Continuous monitoring of respiratory distress by means of SAS/Downe score and oxygen saturation with pulse oximeter was done. All the other vital signs were also taken care of. Time of starting of bCPAP, total duration of therapy are noted. All the collected data while monitoring was documented on monitoring chart for each baby. Neonates were weaned off from bCPAP when there was no respiratory distress or simply if the Downe / SAS scores were $90 \%$ with $\mathrm{FiO} 2$ requirement $92 \%$ were gradually weaned off from the oxygen. Management of other co-morbid conditions such as pulmonary hypertension, shock, seizures, renal dysfunction, therapeutic hypothermia, fluid, electrolyte, acid and base imbalances were at the discretion of the attending physician.

Data was collected in terms of efficacy -Success of bCPAP, gender distribution, gestational age \& birth weight distribution, age at initiation of bCPAP, Changes in Downe/SAS score and total duration on CPAP and outcome-Shifting to mechanical ventilation, complications, mortality \& survival. After the completion of the study, data was analyzed using appropriate statistical methods to find out the efficacy of bubbleCPAP in the treatment of respiratory distress. 21 Babies treated with bubbleCPAP were classified into two groups namely success and failure group and comparison of outcome variables between the groups were carried out. Categorical variables were compared with Chi-square test, while continuous variables were analyzed using Student's t-test for normal distributions. Significance was defined as $\mathrm{P}<0.05$ for the predefined outcome variables. Analysis was done using SPSS software (version 20.0)

\section{Results}

Table 1: BCPAP treatment Efficacy (success /failure) among babies

\begin{tabular}{|c|c|c|c|c|}
\hline \multirow{2}{*}{$\begin{array}{c}\text { Total No. of babies } \\
\text { Treated }\end{array}$} & \multicolumn{2}{|c|}{ Success } & \multicolumn{2}{|c|}{ Failure } \\
\hline & Number & Percentage & Number & Percentage \\
\hline 171 & 118 & $69 \%$ & 53 & $31 \%$ \\
\hline
\end{tabular}

The table shows the efficacy in study group of the CPAP. Among 171 babies, 118 improved with success rate of $69 \%$, whereas 53 babies $(31 \%)$ failed requiring higher mode of ventilation.

Table 2: Gender wise distribution of the study group

\begin{tabular}{|c|c|c|c|c|c|}
\hline \multirow{2}{*}{ Gender } & \multirow{2}{*}{ Total } & \multicolumn{2}{|c|}{ Success } & \multicolumn{2}{c|}{ Failure } \\
\cline { 3 - 6 } & & No. & Percentage & No. & Percentage \\
\hline Male & 106 & 78 & $73.5 \%$ & 28 & $26.5 \%$ \\
\hline Female & 65 & 40 & $61.5 \%$ & 25 & $38.5 \%$ \\
\hline Total & 171 & 118 & & 53 & \\
\hline
\end{tabular}

p-Value 0.0001

Above tables shows that among 171 babies, 106 were males \& 65 were female babies. In males, $73.5 \%$ were in success group and $26.5 \%$ were in failure group. In females, $61.5 \%$ were in success with $38.5 \%$ in failure group.

Table 3: Gestational age wise Distribution of babies and results

\begin{tabular}{|c|c|c|c|c|c|}
\hline \multirow{2}{*}{$\begin{array}{c}\text { Gestational } \\
\text { Age(weeks) }\end{array}$} & \multirow{2}{*}{ Total } & \multicolumn{2}{|c|}{ Success } & \multicolumn{2}{c|}{ Failure } \\
\cline { 3 - 6 } & & No. & Percentage & No. & Percentage \\
\hline $28-30$ & 35 & 14 & $40 \%$ & 21 & $60 \%$ \\
\hline $31-32$ & 34 & 27 & $79.5 \%$ & 7 & $20.5 \%$ \\
\hline $33-34$ & 46 & 34 & $74 \%$ & 12 & $26 \%$ \\
\hline $35-36$ & 18 & 16 & $88.8 \%$ & 2 & $11.2 \%$ \\
\hline $37-38$ & 22 & 18 & $81.8 \%$ & 4 & $18.2 \%$ \\
\hline$>38$ & 16 & 9 & $56.25 \%$ & 7 & $43.75 \%$ \\
\hline Total & 171 & 118 & & 53 & \\
\hline
\end{tabular}

p-Value 0.006

Success rate in 28-30 weeks was $40 \%$, in $31-32$ weeks it was $79.5 \%$, in 33-34 weeks $74 \%$, among 35-36 weeks $88.8 \%$, in $37-38 \%$ it was $81.8 \%$ and in $>38$ weeks of gestational age $56.25 \%$. p-Value was 0.006 . Mean gestational age in the study was $33.63 \pm 3.345$.

Table 4: Efficacy and Distribution of babies based on birth weight

\begin{tabular}{|c|c|c|c|c|c|}
\hline \multirow{2}{*}{$\begin{array}{c}\text { Birth } \\
\text { Weight Gms }\end{array}$} & \multirow{2}{*}{ Total } & \multicolumn{2}{|c|}{ Success } & \multicolumn{2}{|c|}{ Failure } \\
\cline { 3 - 6 } & & No. & Percentage & No. & Percentage \\
\hline$<999$ & 9 & 3 & $33.3 \%$ & 6 & $66.7 \%$ \\
\hline $1000-1500$ & 75 & 46 & $61.4 \%$ & 29 & $38.6 \%$ \\
\hline $1501-2000$ & 42 & 35 & $83.4 \%$ & 7 & $16.6 \%$ \\
\hline $2001-2500$ & 19 & 14 & $73.7 \%$ & 5 & $26.3 \%$ \\
\hline $2501-3000$ & 20 & 15 & $75 \%$ & 5 & $25 \%$ \\
\hline$>3000$ & 6 & 5 & $83.3 \%$ & 1 & $16.7 \%$ \\
\hline Total & 171 & 118 & & 53 & \\
\hline
\end{tabular}

p-Value 0.7 
In $<999$ gms, success rate was $33.3 \%$ and failure $66.7 \%$. In $1000-1500$ gms, success rate was $61.4 \%$ \& failure rate $38.6 \%$. In $1501-2000 \mathrm{gms}$ success rate was $83.4 \%$ with a failure rate $16.6 \%$. The success \& failure rates in 2001-2500 gms were $73.7 \%$ \& $26.3 \%$. In $2501-3000$ gms, $75 \%$ was the success rate and $25 \%$ was the failure rate. There was a success rate of $83.3 \%$ \& failure rate of $16.7 \%$ in $>3000 \mathrm{gms}$. In our study mean birth weight was $1.7242 \pm 0.62345$.

Table 5: Distribution based on Indications for starting bCPAP

\begin{tabular}{|c|c|c|c|c|c|}
\hline \multirow{2}{*}{ Indication } & \multirow{2}{*}{ Total } & \multicolumn{2}{|c|}{ Success } & \multicolumn{2}{c|}{ Failure } \\
\cline { 3 - 6 } & & No. & Percentage & No. & Percentage \\
\hline RDS & 113 & 77 & $68.2 \%$ & 36 & $31.8 \%$ \\
\hline Pneumonia & 31 & 20 & $64.6 \%$ & 11 & $35.4 \%$ \\
\hline MAS & 17 & 11 & $64.7 \%$ & 6 & $35.3 \%$ \\
\hline TTNB & 10 & 10 & $100 \%$ & 0 & $0 \%$ \\
\hline
\end{tabular}

p-Value 0.0001

It was observed that success rate in babies with RDS was $68.2 \%$ \& failure rate was $31.8 \%$. In babies with Pneumonia, success \& failure rates were $64.6 \%$ and $35.4 \%$. Success and failure rates in MAS were found to be $64.7 \%$ \& $35.3 \%$. In TTNB there was $100 \%$ success rate.

Table 6: Distribution of mean age at the time of initiation of treatment

\begin{tabular}{|c|c|c|}
\hline No. of babies & Mean age \pm SD (hours ) & Range (hours) \\
\hline 171 & $9.39 \pm 15.022$ & $1-120$ \\
\hline
\end{tabular}

The mean age for initiation of treatment is $9.39 \pm 15.022$ hours with range of 1-120 hours.

\begin{tabular}{|l|c|c|c|}
\hline Group & Number & Mean \pm SD & Range (hours) \\
\hline Success & 118 & $8.74 \pm 15.373$ & $1-120$ \\
\hline Failure & 53 & $10.85 \pm 14.246$ & $1-84$ \\
\hline
\end{tabular}

Mean age in success group was $8.74 \pm 15.373$ and that of failure group was $10.85 \pm 14.246$.

Table 7: Mean Duration of Treatment in Success and Failure Groups

\begin{tabular}{|c|c|c|}
\hline No. of babies & Mean duration \pm SD (hours ) & Range (hours) \\
\hline 171 & $24.24 \pm 18.22$. & $7-96$ \\
\hline
\end{tabular}

\begin{tabular}{|c|c|c|c|}
\hline Group & Number & Mean \pm SD & Range (hours) \\
\hline Success & 118 & $24.42 \pm 17.726$ & $7-96$ \\
\hline Failure & 53 & $23.83 \pm 19.451$ & $12-86$ \\
\hline
\end{tabular}

p-Value 0.09

Tables shows analysis of the duration of treatment in success and failure groups. The mean duration in success group was $24.42 \pm 17.726$ hours with range of 7- 96 hours. Similarly mean duration of treatment in failure group was $23.83 \pm 19.451$ hours range being $12-86$ hours. Mean duration is $24.24 \pm 18.22$.

Table 8: Downe / SAS score in study group before and after CPAP

\begin{tabular}{|c|c|c|c|c|c|c|}
\hline Downe's/SAS Score & \multicolumn{2}{|c|}{ At Start DS } & \multicolumn{2}{c|}{ After 6hrs } & \multicolumn{2}{c|}{ After 12hrs } \\
\hline & No. & Percentage & No. & Percentage & No. & Percentage \\
\hline$<4$ & 0 & $0 \%$ & 35 & $20.5 \%$ & 88 & $51.5 \%$ \\
\hline 4 & 68 & $39.7 \%$ & 75 & $43.9 \%$ & 36 & $21.0 \%$ \\
\hline 5 & 61 & $35.6 \%$ & 36 & $21.0 \%$ & 25 & $14.7 \%$ \\
\hline 6 & 42 & $24.5 \%$ & 25 & $14.6 \%$ & 19 & $11.11 \%$ \\
\hline 7 & 0 & $0 \%$ & 0 & $0 \%$ & 3 & $1.75 \%$ \\
\hline Total & 171 & & 171 & & 171 & \\
\hline
\end{tabular}

Table shows distribution of babies based on Downe / SAS score. $68(39.7 \%)$ were in score $4,61(35.6 \%)$ were in score $5,42(24.5 \%)$ were in score 6 before institution of CPAP. After 6 hrs of bCPAP, there were $20.5 \%$ of babies with score $<4,43.9 \%$ of babies with score $4,21.6 \%$ with score 5 and $14.6 \%$ were in score 6 . After $12 \mathrm{hrs}$ of bCPAP support, $51.5 \%$ were in $<4$ score, $21 \%$ in score 4 , there were $14.7 \%$ babies in score 5, with $11.11 \%$ babies in score of 6 and score 7 was present in $1.75 \%$ babies. The mean DS at start of bCPAP was $4.85 \pm 0.79$, mean DS after 6hrs of CPAP therapy was $4.30 \pm 0.957$ and mean DS after 12 hrs was $3.83 \pm 1.192$. Out of 171 babies, bubble CPAP was successful in $69 \%$ (118) of babies. The response to bCPAP in studied babies is shown. In the success group, $42.4 \%$, $34.7 \%$ and $22.9 \%$ of the babies had DS of 4,5 and 6 respectively at the start of CPAP therapy. In the failure group $34 \%, 37.7 \% \& 28.3 \%$ of the babies had DS of 4,5 and 6 respectively at the start of CPAP therapy.

Table 9: Response to Bubble CPAP in studied babies ( $\mathrm{n}=171)$

\begin{tabular}{|c|c|c|c|c|c|c|c|}
\hline & & \multicolumn{2}{|c|}{ Success(118) } & \multicolumn{2}{|c|}{ Failure(53) } & \multirow[b]{2}{*}{ Total } & \multirow{2}{*}{ p-Value } \\
\hline & Score & No. & Percentage & No. & Percentage & & \\
\hline \multirow{3}{*}{ At start } & 4 & 50 & $73.5 \%$ & 18 & 26.5 & 68 & \multirow{3}{*}{0.55} \\
\hline & 5 & 41 & $67.2 \%$ & 20 & $32.8 \%$ & 61 & \\
\hline & 6 & 27 & $64.3 \%$ & 15 & $35.7 \%$ & 42 & \\
\hline \multirow{4}{*}{$6 \mathrm{Hrs}$} & $<4$ & 35 & $100 \%$ & 0 & - & 35 & \multirow{4}{*}{0.001} \\
\hline & 4 & 63 & $84 \%$ & 12 & $16 \%$ & 75 & \\
\hline & 5 & 16 & $44.4 \%$ & 20 & $55.6 \%$ & 36 & \\
\hline & 6 & 4 & $16 \%$ & 21 & $84 \%$ & 25 & \\
\hline \multirow{5}{*}{$12 \mathrm{Hrs}$} & $<4$ & 88 & $100 \%$ & 0 & - & 88 & \multirow{5}{*}{0.001} \\
\hline & 4 & 24 & $66.6 \%$ & 12 & $33.4 \%$ & 36 & \\
\hline & 5 & 5 & $20 \%$ & 20 & $80 \%$ & 25 & \\
\hline & 6 & 0 & - & 19 & $100 \%$ & 19 & \\
\hline & 7 & 0 & - & 3 & $100 \%$ & 3 & \\
\hline
\end{tabular}


Table 10: Distribution according to Downe scores at 6 and 12 hours in studied babies with initial score of 4

\begin{tabular}{|c|c|c|c|c|}
\hline \multirow{2}{*}{$\begin{array}{c}\text { Downes } \\
\text { Score }\end{array}$} & \multicolumn{2}{|c|}{ 6Hrs } & \multicolumn{2}{c|}{ 12Hrs } \\
\cline { 2 - 5 } & Success(50) & Failure(18) & Success(50) & Failure(18) \\
\hline$<4$ & $21(42 \%)$ & $0(0 \%)$ & $44(88 \%)$ & $0(0 \%)$ \\
\hline 4 & $25(50 \%)$ & $3(16.7 \%)$ & $5(10 \%)$ & $1(5.6 \%)$ \\
\hline 5 & $4(8 \%)$ & $10(55.6)$ & $1(2 \%)$ & $10(55.6 \%)$ \\
\hline 6 & $0 \%$ & $5(27.7 \%)$ & $0 \%$ & $7(38.9 \%)$ \\
\hline
\end{tabular}

p-Value $<0.05$ p-Value $<0.05$

In the success group, $42 \%$ and $88 \%$ of babies who had a DS of 4 at the start of CPAP therapy improved to a score of $<4$ at 6 hours and 12 hours of CPAP therapy respectively. This was found out to be statistically significant.

Table 11: Distribution according to Downe score at 6 and 12 hours in babieswith initial score of 5

\begin{tabular}{|c|c|c|c|c|}
\hline \multirow{2}{*}{$\begin{array}{c}\text { Downes } \\
\text { Score }\end{array}$} & \multicolumn{2}{|c|}{ 6Hrs } & \multicolumn{2}{c|}{ 12Hrs } \\
\cline { 2 - 5 } & Success(41) & Failure(20) & Success(41) & Failure(20) \\
\hline$<4$ & $14(34.2 \%)$ & $0(0 \%)$ & $28(68.3 \%)$ & $0(0 \%)$ \\
\hline 4 & $20(48.8 \%)$ & $7(35 \%)$ & $11(26.8 \%)$ & $8(40 \%)$ \\
\hline 5 & $7(17 \%)$ & $2(10 \%)$ & $2(4.9 \%)$ & $3(15 \%)$ \\
\hline 6 & $0 \%$ & $11(55 \%)$ & $0 \%$ & $8(40 \%)$ \\
\hline 7 & 0 & 0 & 0 & $1(5 \%)$ \\
\hline
\end{tabular}

p-Value $<0.005$ p-Value $<0.05$

Among the babies having an initial score of 5, 34.2\% and $68.3 \%$ showed improvement to a score of $<4$ at 6 hours and 12 hours of CPAP therapy.

Table 12: Distribution according to Downe score at 6 and 12 hours in babies with initial score of 6

\begin{tabular}{|c|c|c|c|c|}
\hline \multirow{2}{*}{$\begin{array}{c}\text { Downes } \\
\text { Score }\end{array}$} & \multicolumn{2}{|c|}{ 6Hrs } & \multicolumn{2}{c|}{ 12Hrs } \\
\cline { 2 - 5 } & Success(27) & Failure(15) & Success(27) & Failure(15) \\
\hline$<4$ & $0 \%$ & $0(0 \%)$ & $16(59.3 \%)$ & $0(0 \%)$ \\
\hline 4 & $18(66.60 \%)$ & $2(13.3 \%)$ & $8(29.60 \%)$ & $3(20 \%)$ \\
\hline 5 & $5(18.50 \%)$ & $8(53.3 \%)$ & $2(7.40 \%)$ & $7(46.7 \%)$ \\
\hline 6 & $4(14.80 \%)$ & $5(33.3 \%)$ & $1(3.70 \%)$ & $3(20 \%)$ \\
\hline 7 & 0 & 0 & 0 & $2(13.3 \%)$ \\
\hline
\end{tabular}

p-Value 0.0004

Among the babies having an initial score of $6,0 \%$ and $59.3 \%$ of the babies improved to a score $<4$ at 6 hours and 12 hours of bCPAP therapy.

Table 13: Distribution according to SAS score at 6 and 12 hours in babies with RDS

\begin{tabular}{|c|c|c|c|c|}
\hline \multirow{2}{*}{ SAS score } & \multicolumn{2}{|c|}{ 6hrs } & \multicolumn{2}{c|}{ 12 hrs } \\
\cline { 2 - 5 } & Success(77) & Failure(36) & Success(77) & Failure(36) \\
\hline$<\mathbf{4}$ & $23(30 \%)$ & 0 & $55(72 \%)$ & 0 \\
\hline $\mathbf{4}$ & $43(56 \%)$ & 8 & $17(22 \%)$ & 6 \\
\hline $\mathbf{5}$ & $8(10 \%)$ & 15 & $4(5 \%)$ & 16 \\
\hline $\mathbf{6}$ & $3(4 \%)$ & 13 & $1(1 \%)$ & 12 \\
\hline $\mathbf{7}$ & 0 & 0 & 0 & 2 \\
\hline
\end{tabular}

p-Value $<0.05$ p-Value $<0.05$

Significant reduction in SAS score was observed after 6hrs
\& 12 hrs of bCPAP therapy in babies with RDS.

Table 14: Distribution according to Downe /SAS score at 6 and 12 hours in babies with Pneumonia

\begin{tabular}{|c|c|c|c|c|}
\hline \multirow{2}{*}{$\begin{array}{c}\text { Downe/SAS } \\
\text { Score }\end{array}$} & \multicolumn{2}{|c|}{ 6hrs } & \multicolumn{2}{c|}{ 12 hrs } \\
\cline { 2 - 5 } & Success(20) & Failure(11) & Success(20) & Failure(11) \\
\hline$<\mathbf{4}$ & 6 & 0 & 16 & 0 \\
\hline $\mathbf{4}$ & 10 & 3 & 4 & 4 \\
\hline $\mathbf{5}$ & 4 & 3 & 0 & 2 \\
\hline $\mathbf{6}$ & 0 & 5 & 0 & 4 \\
\hline $\mathbf{7}$ & 0 & 0 & 0 & 1 \\
\hline
\end{tabular}

p-Value $<0.05$ p-Value $<0.05$

In babies with Pneumonia, Downe / SAS score reduced significantly after $6 \mathrm{hrs} \& 12 \mathrm{hrs}$ of bCPAP therapy.

Table 15: Distribution according to Downe score at 6 and 12 hours in babies with MAS

\begin{tabular}{|c|c|c|c|c|}
\hline \multirow{2}{*}{$\begin{array}{c}\text { Downe } \\
\text { Score }\end{array}$} & \multicolumn{2}{|c|}{ 6hrs } & \multicolumn{2}{c|}{12 hrs } \\
\cline { 2 - 5 } & Success(11) & Failure(6) & Success(11) & Failure(6) \\
\hline$<4$ & 3 & 0 & 8 & 0 \\
\hline 4 & 5 & 1 & 2 & 2 \\
\hline 5 & 2 & 2 & 1 & 2 \\
\hline 6 & 1 & 3 & 0 & 2 \\
\hline 7 & 0 & 0 & 0 & 0 \\
\hline
\end{tabular}

p-Value $<0.05$ p-Value $<0.05$

Downe score reduced in babies with MAS after 6 hrs \& 12 hrs of bCPAP therapy. Statistically significant difference.

Table 16: Distribution according to Downe score at 6 and 12 hours in babies with TTNB

\begin{tabular}{|c|c|c|}
\hline \multirow{2}{*}{$\begin{array}{c}\text { Downe/SAS } \\
\text { score }\end{array}$} & 6hrs & 12hrs \\
\cline { 2 - 3 } & Success(10) & Success(10) \\
\hline$<4$ & 3 & 9 \\
\hline 4 & 5 & 1 \\
\hline 5 & 2 & 0 \\
\hline 6 & 0 & 0 \\
\hline 7 & 0 & 0 \\
\hline
\end{tabular}

Here also Downe score decreased with bCPAP therapy. In the failure group, none of the babies had a score of 4 at the start of bCPAP therapy. None of the babies having initial score of 5 improved to a score <4. Among the babies who had initial score of 6 , none of the babies had decrease in score at 6 hours and $12.5 \%$ of the babies improved to a score of 5 at 12 hours of bCPAP therapy.

Table 17: Shifting to mechanical ventilation

\begin{tabular}{|c|c|c|c|}
\hline $\begin{array}{c}\text { Mechanical } \\
\text { ventilation }\end{array}$ & Success(118) & Failure(53) & Total \\
\cline { 2 - 4 } & 0 & $53(100 \%)$ & 53 \\
\hline
\end{tabular}

From the above table shifting to mechanical ventilation from the failure group was $100 \%$ compared to success group.

Table 18: Study of complications and morbidity in success and failure

\begin{tabular}{|c|c|c|c|c|c|}
\hline \multirow{2}{*}{ Complications } & \multirow{2}{*}{ Total } & \multicolumn{2}{|c|}{ Success(118) } & \multicolumn{2}{|c|}{ Failure(53) } \\
\cline { 3 - 6 } & & No. & Percentage & No. & Percentage \\
\hline ROP & 7 & 7 & $6 \%$ & 0 & 0 \\
\hline Recurrent Apneoa & 15 & 9 & $7.6 \%$ & 6 & $11.3 \%$ \\
\hline Shock & 20 & 0 & 0 & 20 & $37.8 \%$ \\
\hline
\end{tabular}




\begin{tabular}{|c|c|c|c|c|c|}
\hline Pulmonary Hemorrhage & 17 & 0 & 0 & 17 & $32 \%$ \\
\hline BPD & 6 & 2 & $1.7 \%$ & 4 & $7.5 \%$ \\
\hline Nasal septum injury & 20 & $18(15.3 \%)$ & $2(3.7 \%)$ & - & - \\
\hline & \multicolumn{2}{|c|}{ Success(118) } & ure(53) & & p-Value \\
\hline Complications & $36(30.5 \%)$ & \multicolumn{2}{|c|}{$49(92.5 \%)$} & & 0.0002 \\
\hline
\end{tabular}

Compared to failure and success group, complications were more in failure group. $p$-value $<0.05$, highly significant.

Table 19: Study of mortality in success and failure group

\begin{tabular}{|c|c|c|c|}
\hline & Success & Failure & p-Value \\
\hline Total & 118 & 53 & \multirow{2}{*}{$<0.05$} \\
\hline Mortality & 0 & $43(81 \%)$ & \\
\hline
\end{tabular}

From the above table, mortality rate in the failure group was $81 \%$ compared to success group. P-value is <0.05 significant.

Table 20: Study of Survival in success and failure group

\begin{tabular}{|c|c|c|c|}
\hline & Success & Failure & p-Value \\
\hline Total & 118 & 53 & $<0.05$ \\
\hline Survival & $118(100 \%)$ & $10(20 \%)$ & \\
\hline
\end{tabular}

From the above table, survival rates in success and failure groups were $100 \%$ and $19 \%$ respectively. P-value is $<0.05$ significant. The overall survival rate in the study was came out to be $75 \%$.

\section{Discussion}

This study was a prospective observational study of the neonates with Respiratory distress. The neonates were clinically evaluated and to find out the cause for respiratory distress laboratory investigations were done. Out of 171 babies, 118 babies (69\%) were effectively managed with bubble CPAP. Remaining 53 babies had to be intubated and required more invasive mechanical ventilation. The success rate in Singh et al. ${ }^{[10]}$ study was $54.7 \%$, Sethi et al. ${ }^{[11]}$ study was $60 \%$ and Koti et al. ${ }^{[12]} 75 \%$ was observed.

\subsection{Gender}

In the present study the success rates in males and females were $73.50 \%$ and $61.50 \%$. Parasuramappa et al. study [13] showed a success rate of $61.5 \%$ in males \& $38.5 \%$ in females. In Singh et al., ${ }^{[10]}$ success rates were $55.6 \%$ \& $4.4 \%$ in males and females respectively. In both the studies there was no statistically significant difference in outcome between the two groups, which was found to be similar to Koti et al. ${ }^{[12]}$ and Urs et al. ${ }^{[14]}$ studies. But Sandri F et al. ${ }^{[15]}$ study has shown increased need for respiratory support in male infants.

\subsection{Gestational age}

Present study shows better outcome in 35 - 38 weeks of gestation i.e., $85 \%$ success rate. A statistically significant association was found between bubble CPAP success and gestational age. Similar significant association was found with 32-34 weeks in Parasuramappa et al. study ${ }^{[13]}$. This was similar to the findings in Urs et al. ${ }^{[14]}$. In Singh et al. study ${ }^{[10]} \leq 30$ weeks of gestational age had significant effect on CPAP success which was found similar to the study by Ammari et al. ${ }^{[16]}$. Higher gestational age had a significantly positive effect on the success of bCPAP similar to the study by Hameed et al. ${ }^{[17]}$. This might be because that indication for starting bCPAP was different. The mean gestational age of the babies was $33.626 \pm 3.3449$ weeks in the present study.

\subsection{Birth weight}

In the present study it was observed that there was no significant difference in the outcome of babies based on birth weight ( $\mathrm{p}$-value $>0.05$ ). Urs et al. ${ }^{[14]}$ have shown better outcome in babies with birth weight 1000-1500 gm $(\mathrm{p}<0.001)$. In this study mean birth weight was $1.7515 \pm$ 0.62482 . From this study, observation that with increase in birth weight, bCPAP success rate has increased except for babies in the range of 2000-3000gms which was found out to be similar to Singh et al. ${ }^{[10]}$ but the exception group was babies with weight $\geq 2500$ gms. Probable explanation might be that MAS and pneumonia being the cause of respiratory distress in most of the babies of this weight category.

It was noticed in the study that the gender and mean gestational age had impact on the success of bCPAP which was different from that of the study conducted by Sethi et al. ${ }^{[11]}$

\subsection{Indications}

Success rates in the present study in RDS was $68.2 \%$, in Pneumonia $64.6 \%$, in MAS it was $64.7 \%$ and in TTNB the success rate was $100 \%$. In Bajad et al. study ${ }^{[19]}$ success rate in RDS was $64.5 \%$, in Pneumonia $82 \%$, it was $86 \%$ in MAS and in TTNB group success rate was $100 \%$.

\subsection{Age of initiation}

The mean age for initiation of treatment was $9.39 \pm 15.022$ hours with range of 1-120 hours. Mean age in success group was $8.74 \pm 15.373$ and that of failure group was $10.85 \pm 14.246$. There was no difference in the result with the age of initiation of bCPAP in our study. p-Value 0.15 . It might be due the broad range of age at the time of initiation of bCPAP. In Sethi et al. ${ }^{[11]}$ study found that the age of neonate at which CPAP had been applied median $=2(0.3-$ 6 ) hours of life was a significant contributor for the CPAP failure $(\mathrm{P}=0.024)$ which is different from that found by Koti et al. ${ }^{[12]}(\mathrm{P}$ value $=0.58)$.

\subsection{Duration}

The mean duration on bCPAP in the present study was $24.24 \pm 18.22$ hours. In success group, it was $24.42 \pm 17.72$ hours \& that of failure group $23.83 \pm 19.451$ hours. p-Value 0.09. Singh et al. ${ }^{[10]}$ the mean duration on CPAP was 2.45 \pm 1.27 days, similar reported by Umran et al. ${ }^{[18]} 2.85$ (days) \pm 2.11 , but different with Koti et al., ${ }^{[12]}$ that was 0.97 days. In Sethi et al. ${ }^{[11]}$ study the duration of stay on CPAP was more in success group.

\subsection{Downe/SAS Score}

In this present study of bCPAP, efficacy was judged based on Downes / SAS scoring. In the success group, 42.4\%, $34.7 \%$ and $22.9 \%$ of the babies had DS of 4,5 and 6 respectively at the start of CPAP therapy. In a study conducted by Parasuramappa et al. ${ }^{[13]}$ in the success group, 
$12.1 \%, 51.6 \%$ and $36.3 \%$ of the babies had DS of 4,5 and 6 respectively at the start of CPAP therapy.

Among the babies having an initial score of 5, 63.8\% and $95.8 \%$ showed statistically significant improvement to a score of $<4$ at 6 hours and 12 hours of CPAP therapy. Among the babies having an initial score of 6, 57.6\% and $75.8 \%$ of the babies improved to a score $<4$ at 6 hours and 12 hours of CPAP therapy which was statistically significant. Urs et al. ${ }^{[14]}$ have also shown significant improvement in Downe score after application of bubble CPAP. It was found that there was significant reduction in Downe / SAS scores after 6hrs \& 12 hrs of bCPAP irrespective of the indication for which bCPAP has been started. There was improvement of scores in all the groups i.e., RDS, Pneumonia, MAS \& TTNB with bCPAP.

\subsection{Shifting to mechanical ventilation}

In the present study shifting to mechanical ventilation from the study group was $31 \%$ compared to Koti et al. ${ }^{[12]}$ where it was $25 \%$.

\subsection{Complications and morbidity}

Compared to failure and success group, complications were more seen in failure group. In the present study, $6 \%$ had ROP, Recurrent apnoea was seen in $7.6 \%$, BPD $7.5 \%$ and $3.7 \%$ had nasal septum injury in success group. In the failure group $37.8 \%$ had Shock and pulmonary hemorrhage was present in $32 \%$. Compared to Koti et al., ${ }^{[12]} 5 \%$ babies developed retinopathy of prematurity, apnoea was present in $14.3 \%$ in success group and in failure group $14 \%$ developed shock and apnea in $28.6 \%$.

\subsection{Mortality}

In the present study, mortality rate in the failure group was $81 \%$ compared to success group p-value is $<0.05$ significant. Koti et al. ${ }^{[12]}$ study showed $2.4 \%$ of mortality in success group and $35.7 \%$ in failure group.

\subsection{Survival}

Overall survival rate in the study was found to be $75 \%$. Survival rate in success group was $100 \%$ and in failure group it was $20 \%$. In Iqbal et al. study, ${ }^{[20]}$ survival rate in success group was $97 \%$ and in failure group it was $61 \%$.

\section{Conclusion}

BCPAP was found to be safe, inexpensive and effective means of respiratory support in respiratory distress of any cause and is an effective way of improving oxygenation and can reduce the need for mechanical ventilation. It is effective in both term \& preterm babies with varied respiratory conditions. Use of a bCPAP system to treat neonatal respiratory distress resulted in $75 \%$ absolute improvement in survival. BCPAP can be used as first line respiratory support between nasal oxygen and mechanical ventilation. Starting early bCPAP in neonates with MAS and pneumonia reduces the subsequent need for MV. Both short \& long term complications can be reduced with the use of bCPAP. CPAP appears to be the best option to manage infants with respiratory distress at SNCUs of peripheral levels and to prevent up-transfers to already overburdened Level III / tertiary care centres.

\section{References}

1. Sankar MJ, Neogi SB, Sharma J et al. State of newborn health in India J Perinatol. 2016; 36(s3):S3-S8.

2. Munian D, Biswas RK, Mukherjee R. The Early use of CPAP in Neonatal Pneumonia: Randomized Control Trial. Ann. Int. Med. Den. Res. 2018; 4(2):PE06-PE10.

3. NNF Recommended Basic Perinatal-Neonatal Nomenclature. In: DK Guha, editors. NeonatologyPrinciples and Practice.1st ed. New Delhi: Jaypee Brothers, 1998, 131-2.

4. Silverman WC, Anderson DH. Controlled clinical trial on effects of water mist on obstructive respiratory signs, death rate and necropsy findings among premature infants. Pediatrics. 1956; 17:1-4.

5. Wood DW, Downes' JJ, Locks HI. A clinical score for the diagnosis of respiratory failure Amer J Dis Child. 1972; 123:227-229.

6. Parkash A, Haider N, Khoso ZA et al. Frequency, causes and outcome of neonates with respiratory distress admitted to Neonatal Intensive Care Unit, National Institute of Child Health, Karachi. J Pak Med Assoc. 2015; 65:771-775.

7. Berger TM, Fontana M, Stocker M. The journey towards lung protective respiratory support in preterm neonates. Neonatology. 2013; 104:265-74.

8. Mazzella M, Bellini C, Calevo MG, Campone F, Massocco D, Mezzano P et al. A randomised control study comparing the Infant Flow Driver with nasal continuous positive airway pressure in preterm infants. Arch Dis Child Fetal Neonatal Ed. 2001; 85:86-90.

9. Nowadzky T, Pantoja A, Britton JR. Bubble continuous positive airway pressure, a potentially better practice, reduces the use of mechanical ventilation among very low birth weight infants with respiratory distress syndrome. Pediatrics. 2009; 123:1534-40.

10. Singh et al. Singh HB, Hasthi UR, Ashwani N, Bharadwaj N, Chejeti S. Use of Bubble Continuous Positive Airway Pressure in A Level II Neonatal Intensive Care Unit: A Descriptive Study. Int J Sci Stud. 2017; 5(8):97-100.

11. Sethi A, Mehta NJ, Surti BM, Gamit D, Tada N. Safety And Effectiveness of Bubble Continuous Positive Airway Pressure in Neonates with Respiratory Distress and Its Failure factors. Natl J Med Res. 2015; 5:202-6.

12. Koti J, Murki S, Gaddam P, Reddy A, Reddy MD. Bubble CPAP for respiratory distress syndrome in preterm infants. Indian Pediatr. 2010; 47:139-43.

13. Parasuramappa HSC, Belavadi GB. A descriptive study on the use of bubble CPAP in a level 2 neonatal intensive care unit in Bangalore, India. Sri Lanka Journal of Child Health. 2017; 46(3):211-217.

14. Prashanth S Urs, Firdose Khan, Maiya PP. Bubble CPAP - A primary respiratory support for respiratory distress syndrome in newborns. Indian Pediatrics. 2009; 46:409-411.

15. Sandri F, Ancora G, Lanzoni A et al. Prophylactic nasal continuous positive airways pressure in newborns of 28-31 weeks gestations: multicenter randomized controlled clinical trial. Arch Dis Child Fetal Neonatal Ed. 2004; 89(5):F394-8.

16. Ammari A, Suri M, Milisavljevic V, Sahni R, Bateman D, Sanocka U. Variables associated with the early failure of nasal CPAP in very low birth weight infants. J Pediatr. 2005; 147:341-7.

17. Hameed NN, Abdul Jaleel RK, Saugstad OD. The use of continuous positive airway pressure in preterm 
babies with respiratory distress syndrome: A report from Baghdad, Iraq. J MaternFetal Neonatal Med. 2014; 27:629-32.

18. Umran RM, Al-Musawi J, CABP. Effect of nasal bubble continuous positive airway pressure on neonatal mortality rate in Iraqi Population. Kufa Med J. 2012; 15:92-8.

19. Bajad M, Goyal S, Jain B. Clinical profile of neonates with respiratory distress. Int J Contemp Pediatr. 2016; 3:1009-13.

20. Amjad Iqbal, Talal Waqar C, Aqeel Safdar, Tehreem Iqbal. Experience of nasal continuous positive airway pressure (CPAP) by infant flow driver in a neonatal unit of a developing country. Pak Armed Forces Med J. 2014; 64(1):75-9. 